\title{
Prevalence of Stunting in Children and Adolescents from Bankura District of West Bengal, India
}

\author{
Sudip Datta Banik* \\ Department of Human Ecology, Centro de Investigación y de Estudios Avanzados (Cinvestav) - IPN, Mexico
}

*Corresponding author: Sudip Datta Banik, Department of Human Ecology, Centro de Investigación y de Estudios Avanzados (Cinvestav) - IPN, Mexico.

\begin{abstract}
Under nutrition in children is an important public health issue in India, particularly from the rural areas. The objective of the present study was to evaluate height and prevalence of stunting among school-going children and adolescents. A cross-sectional study was undertaken among schoolgoing children and adolescents from Purulia district in West Bengal, India. The participants were 6 to 9-year-old children (76 boys, 64 girls) and 10 to 17 -year-old adolescents (289 boys, 175 girls). Girl children were taller $(118.44 \mathrm{~cm})$ than boys $(115.72 \mathrm{~cm})$. However, adolescent boys showed higher mean value of height $(141.15 \mathrm{~cm})$ than that recorded among girl peers $(136.94 \mathrm{~cm})$ with significant sex difference. High prevalence of stunting has been recorded among children (boys $46.10 \%$, girls $43.8 \%$ ) and adolescents (boys $77.2 \%$, girls $72.0 \%$ ).

\section{Introduction}

Low height-for-age (stunting) in children and adolescents is an indicator of chronic energy deficiency and growth failure [1] that is related to Social-Economic-Political-Emotional (SEPE) inequalities and insecurities [2]. Poor socioeconomic background, inadequate diet, and unhealthy living conditions may cause under nutrition in children and adolescents [3]. The objective of the present study was to evaluate height and prevalence of stunting among school-going children and adolescents from Purulia district in West Bengal, India.
\end{abstract}

Keywords: Height; Under nutrition; Stunting; Children; Adolescents

\section{Methods}

The study was carried out in 2008 in some selected schools at Kashipur in Purulia district of West Bengal. The sampling was not probabilistic. The study has been approved by the institutional committee before the commencement of work as part of a master's thesis. The parents of the participants gave permission to record anthropometric data from the minors who gave verbal assent. The participants were 6 to 9 -year-old children (76 boys, 64 girls) and 10 to 17 -year-old adolescents (289 boys, 175 girls). Age of the participants has been recorded from the birth certificate issued by the local government authority and decimal age was estimated

from the date of survey. Height was measured to the nearest tenth of a centimeter using a standard stadia meter (Seca, Germany), following standard procedure [4]. Height-for-age Z-scores (HAZ) were calculated using the WHO Anthro and WHO Anthro Plus software and stunting was defined as reported earlier [1]. Data analysis was done using Microsoft $₫$ Excel. Descriptive statistics of age and height (mean values and standard deviation) were calculated and sex difference of characteristics was estimated using Student's t-test. Prevalence of stunting has been estimated. Statistical significance was set a priori at $\mathrm{p}<0.05$. 


\section{Results}

Age (years) and height $(\mathrm{cm})$ showed significant sex differences in children and adolescents except for height in children (Table
1). Girl children were taller than boys. However, adolescent boys were taller than the girl peers. High prevalence of stunting has been recorded among children (boys $46.10 \%$, girls $43.8 \%$ ) and adolescents (boys 77.2\%, girls 72.0\%).

Table 1: Age and height in children and adolescents.

\begin{tabular}{|c|c|c|c|c|c|c|}
\hline \multirow{2}{*}{ Variables } & \multicolumn{3}{|c|}{ Children } & \multicolumn{3}{|c|}{ Adolescents } \\
\cline { 2 - 3 } & Boys (n= 76) & Girls (n= 64) & \multirow{2}{*}{$\mathbf{t}(\mathbf{p}$-value) } & Boys (n= 289) & Girls (n=175) \\
\cline { 2 - 3 } \cline { 5 - 7 } & Mean (SD) & Mean (SD) & Mean (SD) & Mean (SD) & t (p-value) \\
\hline Age (years) & $7.42(1.02)$ & $7.89(1.15)$ & $2.58(<0.05)$ & $14.57(2.34)$ & $13.06(2.19)$ & $6.89(<0.05)$ \\
\hline Height $(\mathrm{cm})$ & $115.72(10.64)$ & $118.44(11.14)$ & $1.47(0.73)$ & $141.15(14.19)$ & $136.94(12.46)$ & $3.25(<0.05)$ \\
\hline
\end{tabular}

\section{Discussion}

The present study shows very high prevalence of stunting in children and adolescents from Kashipur in Purulia district of West Bengal. Prevalence of stunting in children from India has been reported to be high [5]. Previous studies from different districts of West Bengal State also reported high prevalence of stunting in children and adolescents. Studies were cross-sectional in nature. Rate of stunting was $51.7 \%$ and $48.4 \%$ in boys and girls respectively in Barasat and Madhya gram regions near Kolkata [6]. Among Santals (a scheduled tribe) from Birbhum district, children aged 6-10 years were found to be stunted ( $>60 \%$ ) [7]. Remarkable stunting (26\%) was also recorded among 1 to 14-year-old children from Lodha community (a scheduled tribe) in Paschim Medinipur [8]. Nearly 50\% children were stunted among Kora Mudi tribal community in Paschim Medinipur [9]. In Purba, Medinipur district, 9 to 13-year-old Bengali children were stunted (14.6\%) [10]. From Hooghly district, a study reported prevalence of stunting (27\%) among 11 to 18-year-oldadolescent girls [11]. In Puruliya district, frequency of stunting was also high among 5 to 12-year-old Santal boys (22\%) and girls (14\%) [12]. Among 5 to 12 -year-old children from Darjeeling district, boys had higher rate of stunting (37\%) than girls (34.59\%) [13]. Another study from Darjeeling district also reported majority of 11 to 19-year-oldboys (55.4\%) were stunted and the prevalence was much higher than that recorded among girl (25\%) [14]. In conclusion, high prevalence of stunting recorded in the present study shows similar pattern of high-degree under nutrition in school-going children and adolescents reported from other districts of West Bengal that calls for nutrition intervention program.

\section{Acknowledgements}

The author thankfully acknowledges the help and cooperation of the participants and their parents. The author is also thankful toms. Jhuma Mahato for data collection.

\section{Conflicts of Interest}

The author declares no conflict of interest.

\section{References}

1. De Onis M, Onyango AW, Borghi E, Siyam A, Nishidaa C, et al. (2007) Development of a WHO growth reference for school-aged children and adolescents. Bull World Health Organ 85(9): 660-667.

2. Bogin B, Varea C (2020) COVID-19, crisis, and emotional stress: A biocultural perspective of their impact on growth and development for the next generation. Am J Hum Biol Pp. e23474.

3. Scheffler C, Hermanussen M, Bogin B, Liana DS, Taolin F, et al. (2019) Stunting is not a synonym of malnutrition. Eur J Clin Nutr 74(3): 377386.

4. Lohman TG, Roche AF, Martorell R (1988) Anthropometric Standardization Reference Manual. Champagne, IL.

5. UNICEF [2016] Improving Child Nutrition: The achievable imperative for global progress.

6. Bose K, Bisai S, Chakraborty J, Datta N, Banerjee P (2008) Extreme levels of underweight and stunting among pre-adolescent children of low socioeconomic class from Madhyamgram and Barasat, West Bengal, India. Coll Antropol 32(1): 315-319.

7. Chakraborty U, Dutta Chowdhury S, Dutta G, Ghosh T (2008) A Comparative Study of Physical Growth and Nutritional Status in Santal Children of Ghatsila and Bolpur. Tribes and Tribals (Spl vol) 2: 79-86.

8. Bisai S, Bose K, Ghosh A (2008) Prevalence of under nutrition of Lodha children aged 1-14 years of Paschim Medinipur District, West Bengal, India. Iran J Pediatr 18: 323-829.

9. Bisai S, Mallick C (2011) Prevalence of under nutrition among KoraMudi children aged 2-13 years in Paschim Medinipur District, West Bengal, India. World J Podiatry 7(1): 31-36.

10. Datta Banik S, Chatterjee S (2010) Nutritional status of school going children and adolescents aged 9-13 years at Haldia in West Bengal, India. Paediatr Indonesiana 50: 159-165.

11. Pramanik P, Bose Banerjee S, Ghosh A (2014) Lifestyle and nutritional status of school going adolescent girls in a semi urban area of West Bengal, India. IOSR J Dental Med Sci 13(8): 37-42.

12. Dutta Chowdhury S, Chakraborty T, Ghosh T (2008) Prevalence of undernutrition in Santal children of Puruliya district, West Bengal. Indian Pediatr 45(1): 43-46.

13. Mondal N, Sen J (2010) Prevalence of undernutrition among children (512 years) belonging to three communities residing in a similar habitat in North Bengal, India. Ann Hum Biol 37(2): 199-217.

14. Dey I, Biswas R, Ray K, Bhattacherjee S, Chakraborty M, et al. (2011) Nutritional status of school going adolescents in a rural block of Darjeeling, West Bengal, India. The Health 2: 75-77. 